\title{
SOME MISTAKE WHICH OFTEN HAPPENED IN SIMULATION OF INDUCTIVE MODELS IMPLEMENTING
}

\author{
Muchlis \\ Jurusan Kimia FMIPA Universitas Negeri Surabaya \\ Jl. Ketintang Surabaya (60231), Telp. 031-8298761 \\ Email: muchlis_kimia@yahoo.co.id
}

\begin{abstract}
Not forever what written in theory accepted student correctly. Observing is important to check simulation implementing of inductive model by student of Chemistry Education Program of Chemical Department of FMIPA Unesa after they were studying inductive model theory. Observing was conducted since even semester 2012 / 2013 untill even semester 2015 / 2016. Result of observing show there are some mistake which often happened in simulation implementing of inductive model. First mistake is deem that in open-ended phase teacher is obliged to attend the non example of concept, though the non example of concept is not obliged to be attended teacher. Second mistake is teacher teach two concept at the same time in a series of inductive model sintak, though ought to a series of inductive model sintak to teach one concept. Third mistake is example of concept and non example of concept in open-ended is always made more simple than convergent phase so that student respon too varying and it is very difficulty by teacher in convergent phase. Fourth mistake is concept which will reach is not well defined so directingstudent to reach concept is difficulty. Fifth mistake is practice problem in application phase less regarding how is student get concept or not representation of conception which have been reached.
\end{abstract}

Keywords: inductive model, mistake in inductive model implementing

\section{PENDAHULUAN}

Parameter deskripsi capaian Program Studi Pendidikan Kimia FMIPA Universits Negeri Surabaya (Unesa) antara lain mencakup aspek keterampilan khusus yaitu mengaplikasikan keahlian mendidik, meneliti dan mengelola dalam penyelenggaraan pendidikan kimia [1]. Keahlian mendidik antara lain dapat mengaplikasikan model induktif. Model induktif ini termasuk salah satu materi dalam matakuliah Pembelajaran Inovatif 2, Pembelajaran Inovatif 2 mencakup model pembelajaran kooperatif, model pembelajaran langsung, pembelajaran deduktif dan model induktif.

Matakuliah Pembelajaran Inovatif 2 merupakan matakuliah berpraktik artinya bahwa setiap setelah membahas teori model pembelajaran maka dilanjutkan dengan simulasi. Setiap mahasiswa pemrogram matakuliah ini berkesempatan melakukan praktik salah satu model pembelajaran yang menjadi materi matakuliah ini. Seorang mahasiswa dalam simulasi ini bertindak sebagai guru, sementara mahasiswa lainnya bertindak sebagai siswa. Tidak ada skenario naskah seperti film atau drama dalam simulasi ini. "Mahasiswa guru" melaksanakan sintaksintak pembelajaran induktif didukung oleh aktivitas "mahasiswa siswa".

Kegiatan simulasi ini selain sebagai representasi matakuliah berpraktik, juga berfungsi sebagai asesmen perkuliahan. Asesmen adalah suatu proses pengumpulan informasi, dan dalam konteks pengajaran, informasi ini digunakan secara khusus untuk menguji dan menggambarkan performan siswa [2]. Melalui kegiatan simulasi didapatkan informasi apakah mahasiswa telah memahami teoritis model induktif sekaligus mampu menerapkannya dalam pembelajaran. Asesmen memberikan informasi yang dapat membantu meningkatkan pembelajaran siswa dan membantu guru dalam pengajaran [3]. 
Ciri khas model induktif menurut Eggen dan Kauchak [4] adalah 1) merupakan strategi ampuh yang didesain untuk membantu siswa mengembangkan kemampuan berpikir tingkat tinggi dan berpikir kritis pada topik yang spesifik; 2) guru menghadirkan informasi (contoh-contoh dan bila perlu noncontoh) yang menggambarkan topik tertentu (konsep spesifik) dan membantu siswa menemukan pola-pola dalam informasi; 3) siswa mengonstruksi pemahamannya melalui bimbingan yang cermat dan pemberian pertanyaan dari guru; 4) menuntut guru memiliki kemampuan bertanya yang baik untuk menuntun siswa memproses informasi hingga menemukan konsep yang ditargetkan.

Sintak model induktif meliputi lima fase [4] yaitu 1) lesson introduction; 2) OpenEnded Phase; 3) The Convergent Phase; 4) Closure; 5) The Application Phase. Pada fase lesson introduction, guru memfokuskan pada pelajaran, memotivasi, mereview materi sebelumnya yang relevan dan menjaga perhatian siswa. Pada fase Open-Ended, guru menghadirkan contoh-contoh berkualitas yang menggambarkan konsep [5], bila perlu juga menghadirkan noncontoh. Siswa mengamati dan membandingkan informasi (contoh dan noncontoh). Noncontoh bisa dihadirkan ketika siswa kesulitan menemukan pola-pola dalam contoh. Guru meningkatkan keterlibatan siswa melalui pertanyaan yang sifatnya terbuka [5]. Sebisa mungkin semua pendapat siswa ditampung, meskipun menurut guru pendapat siswa itu salah. Pada fase convergent, guru bisa menambahkan contoh atau noncontoh bila siswa belum juga menemukan pola-pola dalam informasil. Selain itu guru juga bisa mengeliminasi jawaban salah siswa, tanpa siswa merasa putus asa karena jawabannya salah. Pada fase closure, siswa diharuskan membuat rangkuman atau menyatakan simpulan yang benar atau mendefinisikan konsep secara benar. Pada fase Application, siswa memberi contoh lain yang sesuai konsep atau guru memberikan contoh dan siswa menjawab contoh dari guru itu.

Sebagus apapun cara penyampaian kepada mahasiswa terkait teoritis model induktif, tidak menjamin mereka dapat mengimplementasikan secara benar model induktif. Oleh karena itu tulisan ini hendak mendiskripsikan kesalahan-kesalahan yang sering terjadi dalam simulasi penerapan model induktif, sebagai langkah pencegahan terjadinya kesalahan yang berlarut-larut pada mahasiswa calon guru.

\section{METODE}

Penelitian ini merupakan penelitian deskriptif. Metode yang digunakan adalah metode observasi. Subyek penelitian adalah mahasiswa Prodi Pendidikan Kimia Jurusan Kimia FMIPA Universitas Negeri Surabaya semester 4 tahun akademik 2012/2013, 2013/2014, 2014/2015 dan 2015/2016.

Instrumen observasi penerapan model induktif dan catatan bebas digunakan dalam penelitian ini. Data selanjutnya dianalisis secara deskriptif untuk mendeskripsikan kesalahan-kesalahan yang sering terjadi selama simulasi penerapan model induktif.

\section{HASILDAN PEMBAHASAN}

Berdasarkan hasil analisis data diperoleh deskripsi kesalahan-kesalahan yang sering terjadi dalam simulasi penerapan model induktif. Kesalahan pertama adalah anggapan bahwa dalam tahap open-ended guru wajib menghadirkan non contoh, padahal non contoh tidak wajib dihadirkan guru. Salah satu contoh dalam simulasi, guru membelajarkan konsep campuran heterogen (zat-zat yang bercampur tidak berada dalam satu fasa), guru menghadirkan contoh sebagaimana dalam Tabel 1.

Tabel 1 Contoh dan noncontoh untuk konsep campuran heterogen

\begin{tabular}{|l|l|}
\hline \multicolumn{1}{|c|}{ CONTOH } & \multicolumn{1}{|c|}{ NON CONTOH } \\
\hline Kopi & $\begin{array}{l}\text { Campuran air dan } \\
\text { garam }\end{array}$ \\
\hline $\begin{array}{l}\text { Campuran air dan } \\
\text { minyak }\end{array}$ & Campuran air dan gula \\
\hline Campuran air dan pasir & Campuran air dan cuka \\
\hline $\begin{array}{l}\text { Campuran air dan } \\
\text { terigu }\end{array}$ & Campuran air dan sirop \\
\hline
\end{tabular}

Sebagaimana dicontohkan dalam Tabel 1, ada contoh dan diikuti noncontoh. Noncontoh boleh dihadirkan ketika siswa kesulitan menemukan karakteristik dari contoh. Karakteristik contoh lebih mudah ditemukan siswa ketika contoh berkualitas [5], informasi yang diperlukan harus tersedia dalam contoh agar siswa mudah mencapai konsep yang ditargetkan. Tabel contoh bisa disusun seperti 
Tabel 2, agar tampak karakteristik yang lengkap tentang "Campuran Heterogen."

Tabel 2 Karaktersitik Contoh

\begin{tabular}{|c|c|c|c|}
\hline CONTOH & $\begin{array}{l}\text { Sifat } \\
\text { campuran }\end{array}$ & $\begin{array}{l}\text { Penyu- } \\
\text { sun }\end{array}$ & $\begin{array}{l}\text { Sifat } \\
\text { Penyusun }\end{array}$ \\
\hline \multirow{3}{*}{ Kopi } & \multirow{3}{*}{$\begin{array}{l}\text { Pahit agak } \\
\text { manis, ada } \\
\text { butiran kopi, } \\
\text { tidak dalam } \\
\text { satu fasa }\end{array}$} & $\begin{array}{l}\text { Serbuk } \\
\text { kopi, }\end{array}$ & pahit \\
\hline & & gula & Manis \\
\hline & & air & tawar \\
\hline \multirow{2}{*}{$\begin{array}{l}\text { Campuran } \\
\text { air dan } \\
\text { minyak }\end{array}$} & \multirow[b]{2}{*}{$\begin{array}{l}\text { Terlihat air } \\
\text { dan minyak } \\
\text { tidak } \\
\text { bercampur } \\
\text { dalam satu } \\
\text { fasa }\end{array}$} & Air & Jernih \\
\hline & & Minyak & $\begin{array}{l}\text { Agak } \\
\text { kental }\end{array}$ \\
\hline \multirow[t]{2}{*}{$\begin{array}{l}\text { Campuran } \\
\text { air dan } \\
\text { pasir }\end{array}$} & \multirow{2}{*}{$\begin{array}{l}\text { Kerikil } \\
\text { mengendap } \\
\text { di dasar } \\
\text { wadah, tidak } \\
\text { larut, tidak } \\
\text { dalam satu } \\
\text { fasa }\end{array}$} & Kerikil & $\begin{array}{l}\text { Lebih } \\
\text { berat } \\
\text { tidak } \\
\text { larut }\end{array}$ \\
\hline & & Air & $\begin{array}{l}\text { Lebih } \\
\text { ringan }\end{array}$ \\
\hline
\end{tabular}

Kesalahan kedua adalah guru mengajarkan dua konsep sekaligus dalam satu rangkaian sintak model induktif, padahal seharusnya satu rangkaian sintak model induktif untuk mengajarkan satu konsep. Satu rangkaian dari fase lesson introduction, openended, convergent, closure hingga fase applicationmerupakan langkah linier untuk membangun satu konsep tertentu. Misalnya ketika dalam simulasi, guru membahas konsep asam menurut Arrhenius, maka guru menghadirkan contoh asam dan noncontoh (berupa basa Arrhenius). Seharusnya pada fase selanjutnya yaitu fase convergent, siswa mengidentifikasi karakteristik contoh (asam), kemudian mendefinisikan asam pada fase closure dan menentukan sesuatu itu asam atau bukan asam pada fase application. Hal ini senada dengan yang dicontohkan Soemiadji [5] ketika membelajarkan konsep arthropoda yang dari fase lesson introduction hingga fase application tetap konsisten membelajar konsep arthropoda. Tetapi sering guru juga mengidentifikasi karakteristik noncontoh (basa) sehingga terbawa terus hingga fase application.

Kesalahan ketiga adalah contoh dan non contoh ditahap open-ended selalu dibuat lebih sederhana dari fase convergent sehingga respon siswa terlalu bervariasi dan ini sangat menyulitkan guru di fase convergent.
Misalnya ketika dalam simulasi, guru hendak membelajarkan konsep isoton (kumpulan unsur-unsur yang memiliki jumlah netron yang sama), maka di fase open-ended guru menghadirkan sebagaimana tertulis dalam Tabel 3.

Tabel3 Contoh

\begin{tabular}{|c|c|}
\hline No & Contoh \\
\hline 1 & ${ }_{5}^{11} \mathrm{~B}$ and ${ }^{12} \mathrm{C}$ \\
\hline 2 & ${ }_{6}^{13} \mathrm{C}$ and ${ }^{14}{ }_{7} \mathrm{~N}$ \\
\hline 3 & ${ }_{6}^{12} \mathrm{C}$ and ${ }^{14} \mathrm{O}$ \\
\hline 4 & ${ }^{3}{ }_{1} \mathrm{H}$ and ${ }_{2}^{4} \mathrm{He}$ \\
\hline 5 & ${ }^{23}{ }_{11} \mathrm{Na}$ and ${ }^{24}{ }_{12} \mathrm{Mg}$ \\
\hline
\end{tabular}

Jika dalam Tabel 3 guru hanya menghadirkan secara global maka akan banyak muncul pendapat yang sebenarnya mungkin benar sesuai contoh tetapi tidak mengarah kepada karakteristik dari contoh yang diinginkan. Salah satu pendapat yang muncul dari tayangan contoh tersebut adalah "kumpulan unsur utama". Pendapat ini sulit dieliminasi. Contoh harus berkualitas yang memuat karakteristik konsep yang sedang dibelajarkan [5].

Seharusnya Tabel 3 dibuat seperti Tabel 4 untuk memudahkan siswa mengidentifikasi informasi dalam contoh. Ada kolom-kolom tambahan yang memuat jumlah proton, elektron dan netron. Dengan demikian siswa bisa melihat pola-pola yang sama dalam contoh yang disajikan.

Tabel4 Contoh

\begin{tabular}{|c|c|c|c|c|c|}
\hline No & Contoh & Unsur & $\Sigma p$ & $\Sigma \mathbf{e}$ & $\Sigma n$ \\
\hline \multirow{2}{*}{1} & \multirow{2}{*}{$\begin{array}{l}{ }_{5}^{11} \mathrm{~B} \text { and } \\
{ }_{12}{ }_{6} \mathrm{C}\end{array}$} & ${ }^{11}{ }_{5} \mathrm{~B}$ & 5 & 5 & 6 \\
\hline & & ${ }_{6}^{12} \mathrm{C}$ & 6 & 6 & 6 \\
\hline \multirow{2}{*}{2} & \multirow{2}{*}{$\begin{array}{l}{ }_{6}^{13} \mathrm{C} \text { and } \\
{ }_{7} \mathrm{~N}\end{array}$} & ${ }_{6}^{13} \mathrm{C}$ & 6 & 6 & 7 \\
\hline & & ${ }^{14} \mathrm{~N}$ & 7 & 7 & 7 \\
\hline \multirow{2}{*}{3} & \multirow{2}{*}{$\begin{array}{l}{ }_{14}^{12} \mathrm{C} \text { and } \\
{ }_{8} \mathrm{O}\end{array}$} & ${ }^{12}{ }_{6} \mathrm{C}$ & 6 & 6 & 6 \\
\hline & & ${ }_{8}^{14} \mathrm{O}$ & 8 & 8 & 6 \\
\hline \multirow{2}{*}{4} & \multirow{2}{*}{$\begin{array}{l}{ }_{1}^{3} \mathrm{H} \text { and } \\
{ }_{2}^{4} \mathrm{He}\end{array}$} & ${ }^{3}{ }_{1} \mathrm{H}$ & 1 & 1 & 2 \\
\hline & & ${ }_{2}^{4} \mathrm{He}$ & 2 & 2 & 2 \\
\hline \multirow[b]{2}{*}{5} & \multirow{2}{*}{$\begin{array}{c}{ }_{11}^{24} \mathrm{Na} \text { and } \\
{ }_{12} \mathrm{Mg}\end{array}$} & ${ }_{11}^{23} \mathrm{Na}$ & 11 & 11 & 12 \\
\hline & & ${ }^{24}{ }_{12} \mathrm{Mg}$ & 12 & 12 & 12 \\
\hline
\end{tabular}


Kesalahan keempat adalah pemilihan konsep yang hendak dicapai tidak terdefinisi dengan baik sehingga siswa sulit diarahkan mencapai konsep. Konsep memiliki 4 komponen [6] yaitu nama, definisi, karakteristik dan contoh. Konsep seperti asam, basa, larutan elektrolit, reaksi redoks dan alkana adalah contoh konsep yang terdefinisi dengan baik. Namun dalam simulasi ada "mahasiswa guru" yang membelajarkan konsep 'hukum kelipatan berganda', 'pemanis buatan' dan 'kecepatan reaksi'. Ketiga konsep terakhir, sulit mencari contoh-contoh yang menggambarkan konsep sehingga ketika dipaksakan diajarkan menggunakan model induktif maka akan sulit mengarahkan siswa menuju konsep tersebut. Model induktif memang unggul dalam mengajarkan konsep [5], tetapi tidak bisa satu model pembelajaran ampuh digunakan untuk mengajarkan semua konsep atau materi pelajaran.

Kesalahan yang kelima adalah soal latihan di tahap application kurang memperhatikan cara siswa memperoleh konsep atau tidak merepresentasikan konsep yang telah dicapai. Sebagai contoh dalam simulasi, guru membelajarkan konsep larutan elektrolit (larutan yang dapat menghantarkan arus listrik). Ketika fase application, guru menyajikan Tabel 5.

Tabel 5 Contoh atau bukan contoh larutan elektrolit

\begin{tabular}{|l|l|l|l|l|}
\hline No & $\begin{array}{l}\text { Nama } \\
\text { Larutan }\end{array}$ & Contoh & $\begin{array}{l}\text { Bukan } \\
\text { contoh }\end{array}$ & Alasan \\
\hline 1. & $\begin{array}{l}\text { Larutan } \\
\text { gula }\end{array}$ & & & \\
\hline 2. & $\begin{array}{l}\text { Larutan } \\
\text { garam }\end{array}$ & & & \\
\hline 3. & $\begin{array}{l}\text { Larutan } \\
\text { urea }\end{array}$ & & & \\
\hline 4. & $\begin{array}{l}\text { Larutan } \\
\text { asam } \\
\text { sulfat }\end{array}$ & & & \\
\hline
\end{tabular}

Guru memberi evaluasi seperti pada Tabel 5 tanpa memberi kesempatan kepada siswa untuk mencoba dengan Avometer untuk menentukan bisa tidaknya menghantar arus listrik. Tentu saja ini tidak mungkin dijawab siswa. Kecuali jika guru mendefinisikan larutan elektrolit adalah larutan yang mengandung zat terlarut yang dapat terurai dalam air seperti senyawa asam, basa atau garam sehingga ada ion-ion dalam air yang berfungsi menghantarkan arus listrik. Ketika siswa telah memahami mana senyawa asam, basa atau garam maka ketika itu juga siswa dapat menentukan suatu larutan itu merupakan larutan elektrolit atau bukan.

\section{SIMPULAN}

Berdasarkan pembahasan, dapat disimpulkan bahwa terdapat kesalahankesalahan yang sering terjadi dalam simulasi penerapan model induktif. Kesalahan pertama adalah anggapan bahwa dalam tahap openended guru wajib menghadirkan non contoh, padahal non contoh tidak wajib dihadirkan guru. Kesalahan kedua adalah guru mengajarkan dua konsep sekaligus dalam satu rangkaian sintak model induktif, padahal seharusnya satu rangkaian sintak model induktif untuk mengajarkan satu konsep. Kesalahan ketiga adalah contoh dan non contoh ditahap open-ended selalu dibuat lebih sederhana dari tahap convergent sehingga respon siswa terlalu bervariasi dan ini sangat menyulitkan guru di tahap convergent. Kesalahan keempat adalah pemilihan konsep yang hendak dicapai tidak terdefinisi dengan baik sehingga siswa sulit diarahkan mencapai konsep.Kesalahan yang kelima adalah soal latihan di faseapplication kurang memperhatikan cara siswa memperoleh konsep atau tidak merepresentasikan konsep yang telah dicapai.

\section{DAFTAR PUSTAKA}

Tim. 2012. Buku Pedoman Mahasiswa Unesa. Syusuurabaya: Unesa Press.

Enger, Sandra K dan Yager, Robert E. 2009. Assessing Student Understanding in Science. United State: Corwin A SAGE Company

Earl, Kerry dan Giles David. 2011. An-other look at Assessment: Assessment in Learning. New Zealand Journal of Teacher'Work, Vol. 8, Issue 1.

Eggen, Paul D dan Kauchak, Donald P. 1995. Strategies for Teacher. United State of America: Allyn and Bacon. 
Soemiadji. 1998. Metode Induktif. Surabaya: Unesa Press.
Widoko.2001. Model Pembelajaran Konsep. Surabaya: Unesa Press 